\title{
A teoria de Mie aplicada ao estudo da banda de absorção de plasmon de superfície de nanopartículas metálicas coloidais
}

\author{
Carlos Rodolfo B. Lopes Souza ; Álvaro Santos Alves ${ }^{2}$ \\ 1. Bolsista PIBIC/CNPq, Graduando em Física, Universidade Estadual de Feira de Santana, e-mail: \\ crblsouza@gmail.com \\ 2. Orientador, Departamento de Física, Universidade Estadual de Feira de Santana, e-mail: asa.@uefs.br
}

PALAVRAS-CHAVE: Teoria de Mie; Espalhamento; Nanopartículas.

\section{INTRODUÇÃO}

Com o avanço na tecnologia de nanofabricação nas últimas duas décadas, os materiais nanoestruturados têm atraído a atenção de pesquisadores devido à suas propriedades físicas únicas, não presentes nos mesmos materiais em dimensões maiores. Tais materiais, em especial as nanopartículas, apresentam aplicações nos mais diversos campos de interesse da indústria, como na fabricação de dispositivos optoeletrônicos (Shirasaki et al., 2013). Nanopartículas de prata apresentam uma faixa de absorção intensa na região UV-Vis conhecida com banda de absorção de plásmon de superfície (SPAB, do inglês surface plasmon absorption band), que ocorre devido as oscilações coletivas dos elétrons na superfície. Em particular, para aplicações em dispositivos optoeletrônicos, em fotônica e no campo emergente da plasmônica, é essencial saber o comportamento óptico das nanopartículas e conhecer a SPAB.

A SPAB de nanopartículas metálicas pode ser obtida pelo método de Mie (Mie, 1908), aplicado com sucesso ao estudo de nanopartículas de prata e ouro. Nessa teoria, a SPAB de nanopartículas esféricas são obtidas através do cálculo da seção de choque de extinção ou eficiência de extinção de nanopartícuas. Neste contexto, o objetivo principal deste trabalho é calcular a banda de absorção de plasmon de superfícies de nanopartículas de prata usando a soma completa da série de Mie para a seção de choque de extinção de partículas de prata esféricas numa gama de raios de 1 a 17 nm e simular o comportamento dessa banda.

\section{MATERIAL E MÉTODOS OU METODOLOGIA (ou equivalente)}

Foi desenvolvido um modelo teórico baseado na teoria de Mie, em que uma onda plana harmônica eletromagnética incide sobre uma partícula esférica, dando origem a um campo eletromagnético espalhado e transmitido ao interior da partícula. Usando o teorema de Poynting, pode-se calcular a contribuição para energia advinda dos campos espalhados e absorvidos pela partícula. A partir daí a seção de choque de extinção e de espalhamento pode ser obtida em função dos parâmetros da nanopartícula e do meio envolvente: os índices de refração e o tamanho da partícula.

Além disso, simulações foram feitas usando o pacote computacional MiePlot, para compreender o comportamento da SPAB das nanopartículas com o raio variando de $1 \mathrm{~nm}$ a $17 \mathrm{~nm}$. 


\section{RESULTADOS E/OU DISCUSSÃO (ou Análise e discussão dos resultados)}

O gráfico na Fig. 1 abaixo sumariza o resultado da simulação do nosso modelo para seção de choque de absorção para as nanopartículas de prata imersas na água, para valores do raio de 5, 8, 11, 14 e $17 \mathrm{~nm}$, em termos do comprimento de onda da radiação:

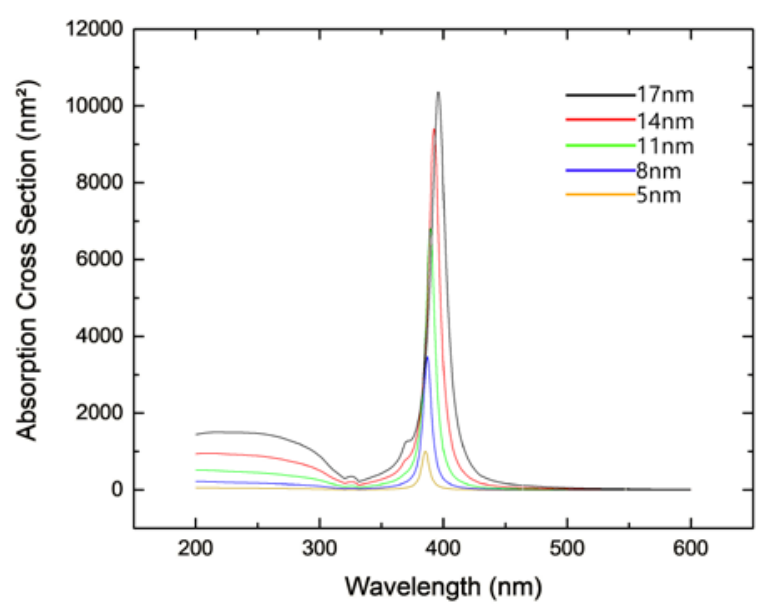

Figura 1: Seção de choque de absorção para nanopartículas de prata em meio aquoso com raio variando de 5 a $17 \mathrm{~nm}$.

Os resultados da simulação mostram que a banda de absorção fica mais intensa a medida que o raio cresce, na região entre $380-400$ nm, no UV-vis. Além disso, com o aumento das nanopartículas, há um deslocamento do pico da banda de absorção para regiões de menor energia. Esse comportamento pode ser observado no gráfico da Fig. 2, que relaciona o raio com a posição do pico da banda de absorção:

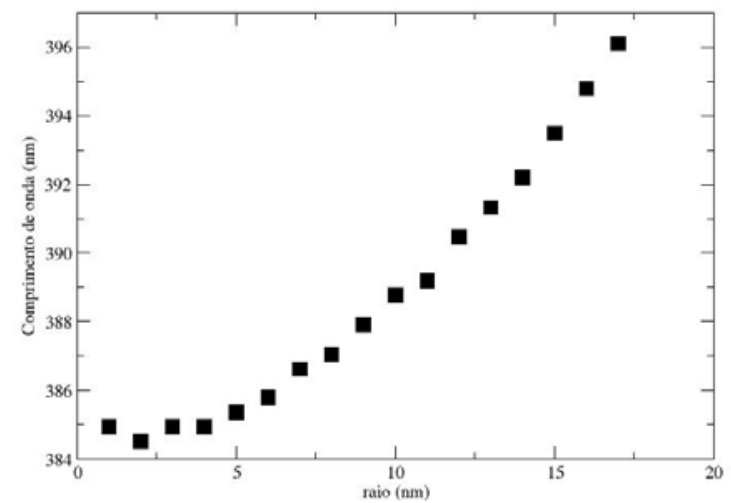

Figura 2: Posição do pico da banda de absorção para cada valor do raio das nanopartículas.

Esse comportamento já era esperado, uma vez que aumentando o tamanho da nanopartícula, diminui-se a região de confinamento dos elétrons, isto é, dos plásmons de superfície, de forma que a diferença de energia entre os níveis seja menor e consequentemente, a absorção ocorre em frenquências menores. Frisamos ainda que a teoria de Mie só descreve a faixa de absorção das nanopartículas, não explica porque a banda de absorção varia com a mudança dos parâmetros do material, pois tais efeitos só podem ser explicados corretamente através da teoria quântica e fogem do escopo deste trabalho. 


\section{CONSIDERAÇÕES FINAIS (ou Conclusão)}

Neste trabalho, foi estudado a teoria de espalhamento Mie e desenvolvido um modelo teórico para o cálculo da seção de choque de absorção de nanopartículas de prata. Com o método desenvolvido, foi possível determinar a banda de absorção de plasmon de superfície das nanopartículas, o que possibilita caracterização óptica de sistemas coloidais com raio variando de $1 \mathrm{~nm}$ a $17 \mathrm{~nm}$, imersas em meio aquoso. Os resultados teóricos foram simulados computacionalmente usando o pacote MiePlot, mostrando que o pico de absorção das nanopartículas cresce com o aumento do raio das nanopartículas, numa faixa que cobre de aproximamente $380 \mathrm{~nm}$ a $400 \mathrm{~nm}$ do espectro UV-próximo. Além disso, há um deslocamento do pico para regiões mais próximas do visível com o aumento das nanopartículas.

\section{REFERÊNCIAS}

MIE, Gustav. Beiträge zur Optik trüber Medien, speziell kolloidaler Metallösungen. Annalen der physik, v. 330, n. 3, p. 377-445, 1908.

SHIRASAKI, Yasuhiro et al. Emergence of colloidal quantum-dot light-emitting technologies. Nature Photonics, v. 7, n. 1, p. 13, 2013. 